\title{
Simultaneous Bilateral Tubal Ectopic Pregnancy after Intracytoplasmic Sperm Injection and Embryo Transfer, in a Patient with Stage 3 Endometriosis
}

\author{
Baghdadi ${ }^{2}$, Bordes A $^{2}$, Salle B $^{2}$ and Lamblin $\mathbf{G}^{1}$ \\ ${ }^{1}$ Department of Obstetrics and Gynaecology, Femme-Mère-Enfant University Hospital, Bron, France \\ ${ }^{2}$ Department of Reproductive Medicine, Femme-Mère-Enfant University Hospital, Bron, France
}

*Corresponding author: Tariq Baghdadi, Department of Obstetrics and Gynaecology, Femme-Mère-Enfant University Hospital, 59 Boulevard Pinel, 69677 Bron, France, Tel: 0033624072462; Fax:0033427869267; E-mail: al_saher999@hotmail.com

Received date: 25 October, 2016; Accepted date: 4 November, 2016; Published date: 6 November, 2016

Citation: Baghdadi T, Bordes A, Salle B, et al. Simultaneous bilateral tubal ectopic pregnancy after intracytoplasmic sperm injection and embryo transfer, in a patient with stage 3 endometriosis. Gynecol Obstet Case Rep 2016, 2:3.

\section{Abstract}

Objective: To describe a simultaneous bilateral tubal ectopic pregnancy after intracytoplasmic sperm injection and embryo transfer: A case report.

Setting: Department of Reproductive Medicine, FemmeMère-Enfant University Hospital, Bron, France.

Introduction: The incidence of extra-uterine pregnancy increases to $2 \%$ to $12 \%$ following IVF-ET; several pathogenic theories have been suggested, including abnormal hormonal secretion or exogenous hormones administered in assisted reproductive technology (ART).

Patient and method: A 32year-old nulliparous woman, with primary infertility and endometriosis stage 3 , was treated by ART with intracytoplasmic sperm injection and embryo transfer.

Result: The patient showed simultaneous bilateral extrauterine pregnancy, managed by laparoscopic salpingectomy.

Discussion: The various possible pathophysiological mechanisms are described, with a review of the literature on simultaneous bilateral extra-uterine pregnancy following ART.

Conclusion: In pregnancies following ART, ectopic pregnancy should always be screened for by serum hCG monitoring and transvaginal ultrasound until the implantation site can be confirmed, as incidence is higher than in spontaneous pregnancy. Even if serum hCG concentration increases normally, possible bilateral EP should always be investigated if no intrauterine gestational sac can be seen.

Keywords: Bilateral ectopic pregnancy; IVF; ICSI; ET; Endometriosis

\section{Introduction}

The rate of ectopic pregnancy (EP) is $2 \%$ of all pregnancies, and higher in case of assisted reproductive technology (ART). In the USA in 1999, EP was found in $2.2 \%$ of all pregnancies from in vitro fertilization (IVF) and in $1.9 \%$ of those from intracytoplasmic sperm injection (ICSI), and in France in the same year in $3.4 \%$ and $1.9 \%$ respectively [1]. Steptoe and Edwards reported the first case of EP after IVF and embryo transfer (ET) in 1976 [2]. Bilateral tubal pregnancy is a rare clinical condition with an incidence of 1 in 200,000 pregnancies $[3,4]$, and is very rare after ART, with only a few case reports: in 1983, Trotnow et al. reported the first case after IVF-ET [5], and Kahraman et al. the first case after ICSI, in 1995 [6].

The present case of bilateral tubal pregnancy occurred in a patient undergoing ICSI with embryo transfer (ET) in day 2 after ICSI for infertility secondary to grade-3 endometriosis, with isolated asthenospermia as a male factor.

\section{Patient sand Method}

A 32-year-old G1P0 woman had history of first trimester miscarriage in 2011, and grade-3 endometriosis discovered in 2009 during diagnostic laparoscopy for dysmenorrhea, with removal of a $6 \mathrm{~cm}$ ovarian cyst; methylene blue dye test was positive bilaterally, demonstrating tubal permeability. She had been consulting in our infertility clinic in 2013 for secondary infertility for 2 years since the early miscarriage in 2011. MRI showed recto-vaginal nodular adhesion with left ovary endometrial cyst. Serology (chlamydia, mycoplasma) was negative and anti-Müllerian hormone (AMH) concentration was $4.66 \mathrm{ng} / \mathrm{ml}$. On the other side, there was isolated asthenospermia as a male factor.

It was decided to perform down-regulation with $\mathrm{GnRH}$ agonist from day 21 of the last menstrual period (Decapeptyl, $\left.0.1 \mathrm{mg}^{\circledR}\right)$, followed by recombinant follicle-stimulating hormone stimulation (Puregon Pen ${ }^{\circledR}, 300$ IU). Thirty-six hours after induction of ovulation by human chorionic gonadotropin (hCG: Ovitrelle ${ }^{\circledR}$ ) on day 12 after stimulation, egg collection retrieved 10 ovocytes. Two embryos were transferred in day 2 
after ICSI by a Ellios catheter in $15 \mu \mathrm{l}$ transfer medium and 2 embryos was frozen at the blastocyst stage (days 5 and 6). The luteal phase was supported with progesterone (Utrogestan ${ }^{\circledR}$, $600 \mathrm{mg}$ per day). On day 15 after ET, hCG concentration was $242 \mathrm{IU} / \mathrm{L}$ and 1,383 IU/L $48 \mathrm{~h}$ later.

\section{Results}

The patient presented in the gynaecology emergency department 19 days after ET for right iliac fossa pain without vaginal bleeding. hCG was 2,377 IU/L and vaginal ultrasound found no intrauterine gestational sac, lateral uterine mass or free fluid in the recto-uterine pouch; the only positive finding was the $40 \mathrm{~mm}$ right ovarian endometrial cyst, which had been known for 1 year. The patient was admitted for observation. At $48 \mathrm{~h}$, hCG concentration was 7,722 IU/L, and control ultrasound showed free fluid and a $10 \mathrm{~mm}$ left adnexal mass (Figure 1).

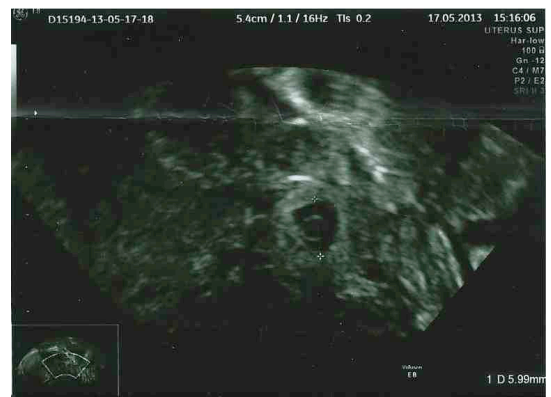

Figure 1 Ultrasound image of the left side ectopic pregnancy

Laparoscopic left salpingectomy was immediately performed for left ampullary EP and moderate bleeding; the right tube was slightly distended with important adhesions and impossibility to differentiate if there was another EP, and was therefore conserved, with postoperative hCG monitoring. The patient was discharged on day 1 after surgery in good condition with a decreased level hCG at 3,780 IU/L.

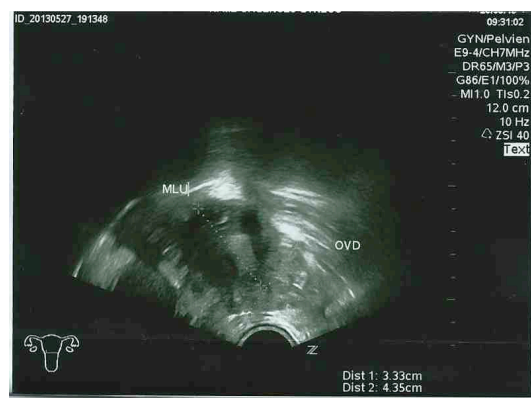

Figure 2 Ultrasound image of the right side ectopic pregnancy

48 hours after discharge, her hCG level was 1,980 IU/L. One week later, she consulted again in the emergency department with right iliac fossa pain with guarding and no rebound tenderness, associated with mild vaginal bleeding. Ultrasound found a 4-mm right adnexal mass and free fluid (Figure 2); hCG concentration was $3,520 \mathrm{IU} / \mathrm{L}$. Laparoscopic right salpingectomy was performed for distended right tubal EP and severe bleeding.

The patient was discharged on postoperative day 2 in good condition with hemoglobin at $9 \mathrm{~g} / \mathrm{L}$ and serum hCG at 1,103 IU/L (returning to zero 2 weeks after discharge); histopathological examination confirmed bilateral tubal pregnancy.

\section{Discussion}

There are several theories about the genesis of EP and its physiopathology is well known: endosalpinx lesion (tubal factor) is one important factor [7-10], induced by sexually transmitted infection, distortion of pelvic anatomy caused by diseases such as endometriosis or by adhesion after previous surgery, history of EP or hormone concentration imbalance during the menstrual cycle [11].

Incidence in IVF-ET increases to $2 \%$ to $12 \%[12,13]$, and seems to be related to abnormal hormonal secretion or exogenous hormones administered in ART (notably the smooth muscle relaxant effects of progesterone in luteal support [14]; incidence may increase with the number of transferred embryos [15]; the volume of transfer medium may also be implicated, and it is recommended that it should not exceed $20 \mu \mathrm{l}$ [16]. Dubuisson et al. [8] reported a $2 \%$ incidence of EP after embryo transfer in $10 \mu \mathrm{l}$ to $20 \mu \mathrm{l}$ of fluid, although other authors did not confirm these findings $[17,18]$. Knutzen et al. [19] reported tubal reflux in $38 \%$ of patients undergoing mock transfer of $40 \mu$ of radiopaque dye.

In the particular case of bilateral EP after ART, three theories have been suggested. Firstly, embryos may be directly injected into the tubes. Secondly, embryos may be transferred correctly to the endometrial cavity but regressively migrate to the tubes as consequence of endometrial secretion. The third theory involves a "spray effect" during transfer whereby embryos might be pushed toward the tubal portions; in healthy functioning tubes, however, they should return to the endometrial cavity, further suggesting that tubal impairment can increase EP risk $[11,20,21]$.

The present case involved no EP risk factors other than ART and advanced endometriosis; the latter plays an important role in increasing the probability of EP, causing intrinsic tubal pathologies such as tubal endosalpingiosis that may also account for EP.

\section{Conclusion}

Ectopic pregnancy after in vitro fertilization is becoming more frequent with the development of assisted reproductive technology. In case of pregnancy after ART, EP should always be screened for by serum hCG monitoring and trans-vaginal ultrasound until the implantation site can be confirmed, as incidence is higher than in spontaneous pregnancy. And in case of transfer of 2 embryos we should be careful even if serum hCG concentration increases normally, possible bilateral EP 
should always be investigated if no intrauterine gestational sac can be seen: in the present case, serum hCG levels were doubling normally, but there was no intrauterine image. Another important point during ART is that, in case of unilateral EP, the situation of the other tube should be systematically checked and hCG levels should be monitored until negative; in the present case, distention of the other tube was mild; but, as the patient was known to have severe endometriosis with several peritoneal adhesions, it was decided to continue hCG monitoring, which decreased after the first operation but then increased one week later.

\section{References}

1. Patil M (2012) Ectopic pregnancy after infertility treatment. J Hum Reprod Sci 5: 154-165.

2. Steptoe PC, Edwards RG (1978)Birth after the reimplantation of a human embryo. Lancet 12: 366.

3. Jonler M, Rasmussen KL, Lundorff $P$ (1995) Coexistence of bilateral tubal and uterine pregnancy. Acta Obstet Gynecol Scand 74: 750-752.

4. Stewart HL (1950) Bilateral ectopic pregnancy. West J Surg Obstet Gynecol 58: 648-650.

5. Trotnow S, Al-Hasani S, Hünlich T, Schill WB (1983) Bilateral tubal pregnancy following in vitro fertilization and embryo transfer. Arch Gynecol 234: 75-78.

6. Kahraman S, Alatas C, Tasdemir M, Nuhoglu A, Aksoy S, et al. (1995) Simultaneous bilateral tubal pregnancy after intracytoplasmic sperm injection. Hum Reprod 10(12): 3320-3321.

7. Strandell A, Thorburn J, Hamberger L (1997) Risk factors for ectopic pregnancy in assisted reproduction. Fertil Steril 71 282-286.

8. Dubuisson J, Aubriot F, Mathieu L, Foulot H, Mandelbrot L, et al. (1991) Risk factors for ectopic pregnancy in 556 pregnancies after in vitro fertilization: implications for preventive management. Fertil Steril 56: 686-690.

9. Verhulst G, Camus M, Bollen N, Van Steiterghem A, Devroey P (1993) Analysis of risk factors with regard to the occurrence of ectopic pregnancy after medically assisted procreation. Hum Reprod 8: 1284-1287.
10. Herman A, Ron-El R, Golan A, Weinraub Z, Bukovsky I, et al. (1990) The role of tubal pathology and other parameters in ectopic pregnancies occurring in in vitro fertilization and embryo transfer. Fertil Steril 54: 864-868

11. De Los Ríos JF, Castañeda JD, Miryam A (2007) Bilateral ectopic pregnancy. J Minim Invasive Gynecol 14: 419-27.

12. Serour GI, Aboulghar MD, Mansour R, Sattar MA, Amin Y, et al. (1998) Complications of medically assisted conception in 3,500 cycles. Fertil Steril 70: 638-642

13. Pyrgiotis E, Sultan KM, Neal GS, Liu HC, Grifo JA, et al. (1994) Ectopic pregnancy after in-vitro fertilization and embryo transfer. J Assist Reprod Gen 11: 79-84.

14. Garmel SH (2003) Early Pregnancy Risks. In: Decherney AH, Nathan L (Eds). Current obstetric \& gynecologic diagnosis \& treatment. New York: McGraw Hill 272-85.

15. Pan HS, Chuang J, Chiu SF, Hsieh BC, Lin YH, et al. (2002) Heterotopic triplet pregnancy: report of a case with bilateral tubal pregnancy and an intrauterine pregnancy. Hum Reprod 17: 1363-1366.

16. Lee JD, Chang SY, Chang MY, Lai YM, Soong YK (1992) Simultaneous bilateral tubal pregnancies after in vitro fertilization and embryo transfer: report of a case. J Formos Med Assoc 91: 99-101.

17. Cohen J, Mayoux MJ (1986) Grossesse ectopique après fécondation in vitro et transfert d'embryon. Contracept Fertil Sex 14: 999-1001.

18. Diedrich K, Van der Ven H, Al-Hasani S, Krebs D (1989) Establishment of pregnancy related to embryo transfer techniques after in-vitro fertilization. Hum Reprod 4: 111-114.

19. Knutzen V, Stratton CJ, Sher G, McNamee PI, Huang TT, et al. (1992) Mock embryo transfer in early luteal phase. The cycle before in vitro fertilization and embryo transfer: a descriptive study. Fertil Steril 57: 156-162.

20. Issat T, Grzybowski W, Jakimiuk AJ (2009) Bilateral ectopic tubal pregnancy, following in vitro fertilisation (IVF). Folia Histochem Cytobiol 47(5): S147-148.

21. Hewitt J, Martin R, Steptoe PC, Rowland GF, Webster J (1985) Bilateral tubal ectopic pregnancy following in-vitro fertilization and embryo replacement. Case report. $\mathrm{Br} J$ Obstet Gynaecol 92(8): 850-852. 